\title{
An Evaluation OfSoil Condition And Flood Risk For Road Network Of Bangladesh-Compiled From Engineering Soil Maps And Digital Elevation Model
}

\author{
*Md. Abdullah Al Mamun ${ }^{1}$, Salma Akter Khuky ${ }^{1}$,Annesha Das Hasi ${ }^{1}$, \\ Nasim Ferdous ${ }^{2}$ \\ ${ }^{I}$ Bangladesh Road Research Laboratory, Roads and HighwaysDepartment, Bangladesh \\ ${ }^{2}$ Department of Disaster Science and Management, University of Dhaka, Bangladesh \\ Corresponding Author: Md. Abdullah Al Mamun
}

\begin{abstract}
Bangladesh is a country where the river bearing soft sediments are covering all over. Moreover, natural hazards strike this country almost every year. So, civil engineering constructions should take consideration of these aspects in the planning stage. This article attempts evaluation of soil condition of Bangladesh and flood hazard assessment regarding road network of Bangladesh. Two maps were engendered to serve the purpose, one showing soil condition and other illustrating flood vulnerability. It has been revealed from the study that some roads in Bangladesh are lying on soft soil with less engineering value, also some are in areas which are vulnerable for being affected by flood hazard. It is expected that this study would be helpful for planners, decision makers, and civil engineers for constructing endurable network in Bangladesh and thus contribute towards sustainable development of the country.
\end{abstract}

Keywords:Road network of Bangladesh, Soil condition, Engineering soil mapping, Elevation mapping of Bangladesh, Flood hazard.

\section{Introduction}

Bangladesh is covered all over by sediments beared from the Himalayan mountain belt by GangesBrahmaputra-Meghna (GBM) River system, among which the top soils are mostly soft alluvium, having less engineering significance. Therefore, any engineering construction here needs prior evaluation of ground condition. Moreover, Bangladesh is a disaster prone country [1] — natural hazards not only cause loss of life but also damage of properties and critical life line like roads and highways, water supply, etc. So, assessment of hazard risk is also another criteria for infrastructure development.

Roads and Highways Department is responsible for the construction and maintenance of the major road network of Bangladesh. The mission of the Roads and Highways Department is to provide safe, cost effective roads and bridges. To construct safe, cost effective roads and bridges, an engineering soil map may play an important role as a planning tool. If we have appropriate information regarding soils of Bangladesh, we can plan, design and construct roads and bridges economically and provide safety during construction. To prepare an engineering soil map of Bangladesh, it needs both time and manpower. Thus the engineering soil map of whole Bangladesh cannot be made all at once. It is a continuous process and has to be made in phase. Bangladesh Road Research Laboratory (BRRL)prepared Engineering soil map of 49 districts of Bangladesh. As a part of the continuous process in financial year 2016-2017, an initiative was taken to complete mapping of the remaining districts and compiling all the previous maps under the supervision of BRRL.The Government of the People's Republic of Bangladesh allocated public funds for the cost of engineering soil map of Bangladesh by sub-soil investigation under BRRL during the year 2013-16 [2].To prepare an engineering soil map of Bangladesh, it needs both time and manpower. Thus the engineering soil map of whole Bangladesh cannot be made at once. Therefore, the engineering soil map of Bangladesh was made in three phases.A compilation of these maps along with overlying the current road network of Bangladeshto assess soil condition underneath those roads and recommendation for future road network is one of the principal concerns of this article. Evaluation of soil condition is essential to minimize maintenance cost. This map would help decision makers, planners, and civil engineering to take appropriate action prior construction of roads.

Bangladesh is affected by flood in almost every year. Which also affects badly the road network. So, prior knowledge about the zones which are flood prone is necessary. Preparation of elevation map from digital elevation model (DEM) with an overlying road network of Bangladesh to assess flood hazard is another scope of this article. 


\section{General Geology And Surface Geology}

Bangladesh occupies most of the part of the Bengal Basin [3] and lies on the eastern margin of the Precambrian Indian shield, where there the Indian plate is subducting beneath the Burmese platelet [4] [5]. The Bengal Basin includes Bangladesh, western part of West Bengal state, and Tripura state of India. It is bounded by Shillong massif to the north, frontal fold belt of Indo-Berman range to the east, Precambrian Indian shield to the west and open to the south for some distance to the Bay of Bengal. Basin fill history of Bengal Basin is gradual in nature. It ranges from the pre collision marine phase to post collision fluvial phase. Sedimentation in the basin can be broadly subdivided into five major phases [6]:

I. Permo-Carboniferous to Early Cretaceous.

II. Cretaceous to Mid-Eocene.

III. Mid-Eocene to Early Miocene.

IV. Early Miocene to Mid-Pliocene.

V. Mid Pliocene to Quaternary.

\subsection{Surface geology of Bangladesh}

Geology focuses on the nature and properties of rocks and sediments. A good knowledge on the geology of the rocks and sediments is indispensable to understand the nature and properties of the parent materials. It is essential to understand the processes of formation of major soils of the country. Geomorphological knowledge is also important to visualize the processes and methods well. Bangladesh lies in an active seismic location. Moreover, being a riverine country, the sediments are much affected by the combination of river process and seismic activity. The rivers are the most significant features of Bangladesh geology. They constantly change course, sometimes so rapidly that it cannot be predicted. As a result the topological features of Bangladesh are ever changing and it gives a spectacular feature of surface geology. Fig. 2 represents surface geology units of Bangladesh.

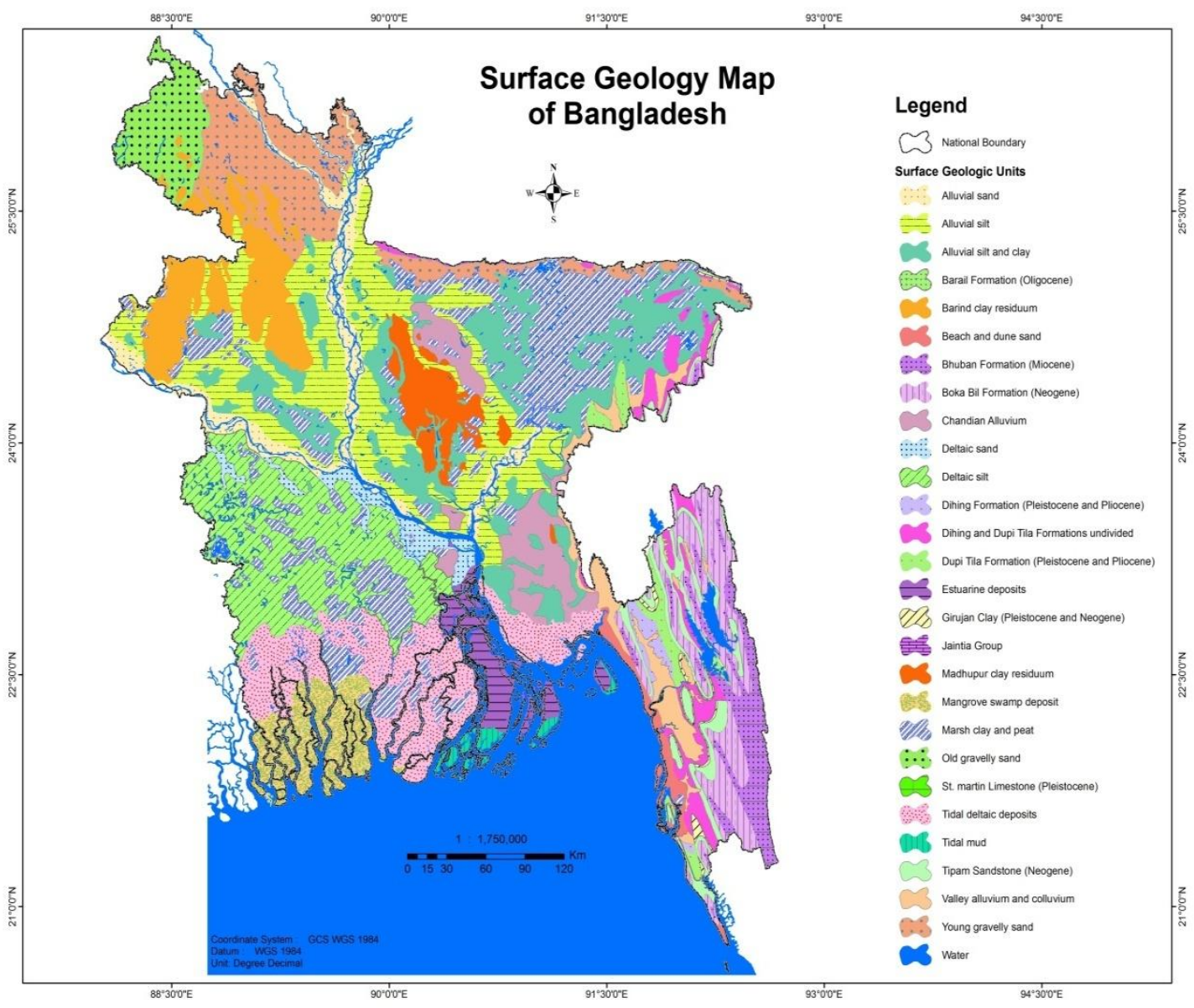

Figure 1: Surface geology map of Bangladesh showing surface geology units of the country. 


\section{Methodology}

To prepare engineering soil map as per soil classification for road master plan involved the following procedure:

- Collection of around 50 secondary borehole data for each of divisions.

- Three standard penetration test (SPT) borehole were completed for each district.

- With the help of these data engineering soil maps were prepared in GIS environment.

- Compilation of all the soil maps of previous and new (KML/KMZ file for Google earth presentation) to make it user friendly.

Soil properties are subjected to high spatial and temporal variations. For accurate assessment of soil properties, high-density sampling is a prerequisite, but borehole sampling and other geophysical tests are costly. Therefore, the secondary borehole has been collected from government and/or non-government organizations. Regional geomorphology was also taken into consideration during soil mapping. Locations where primary and/or secondary data were used are manifested in Fig. 2.Phase wise engineering soil map locations are given in Fig. 3. and also represented in Table 1. SPT N value based soil consistency and soil type from borehole samples were mainly considered during engineering soil mapping for this study.

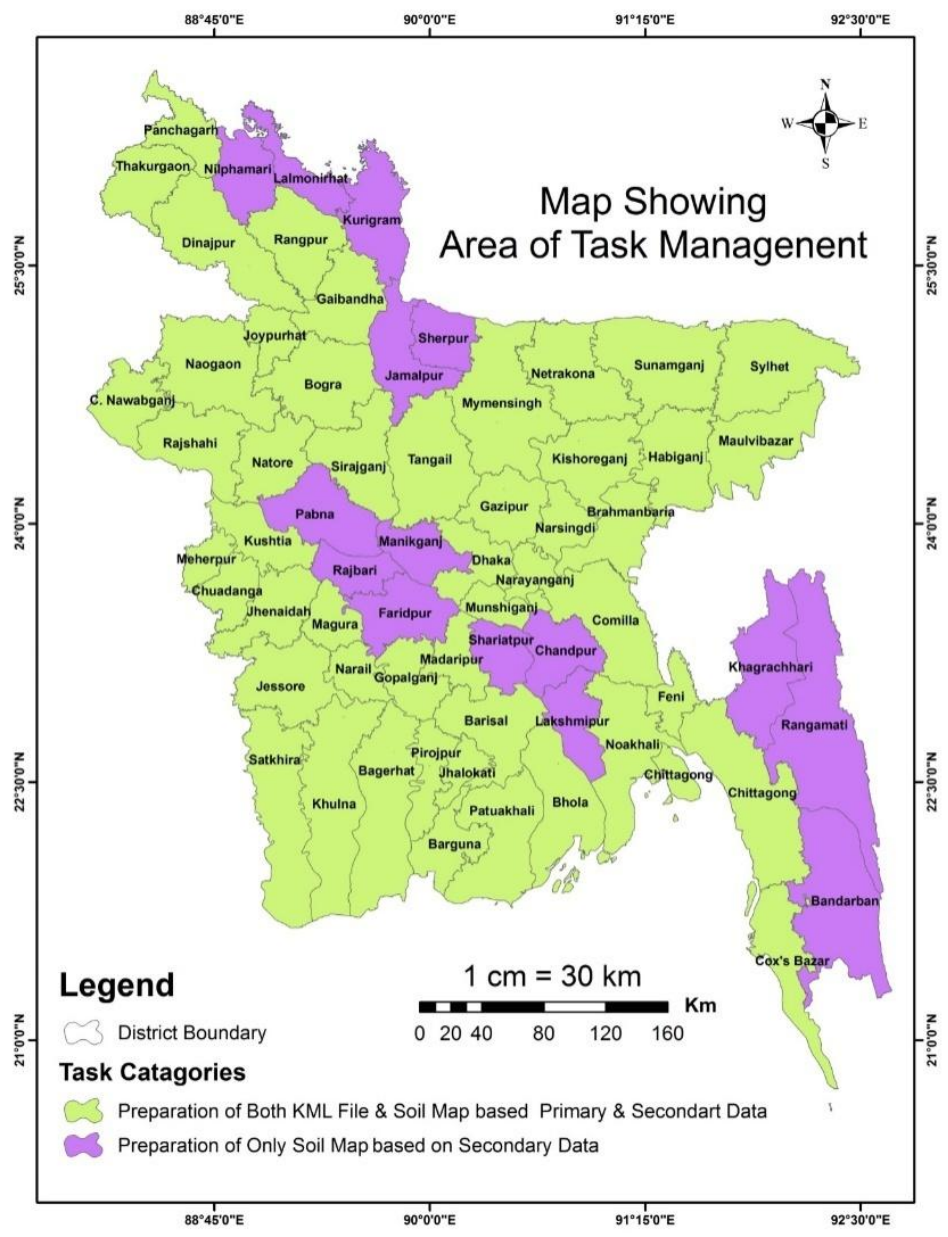

Figure 2: Engineering soil map locations where primary and/or secondary were used.

Those maps have been accomplished in a different financial year (Table 1). First of all, the Primary borehole data collection is very essential part to conduct this study successfully. All data are preserved in Bangladesh Road Research Laboratory's archive as well as assigned organization/consultancy firm. Initially,primary data and existing engineering soil maps were collected. After that borehole data have been summarized and prepared for GIS map presentation. Later, existing engineering soil maps were compiled for demonstration. Finally derived a map exhibiting road network of Bangladesh alongside respective soil condition (Fig. 4). 
Table 1: Phase wise engineering soil mapping locations for Bangladesh, completed by BRRL.

\begin{tabular}{|c|c|l|}
\hline Financial year and phase & Package & Districts/Divisions \\
\hline \multirow{3}{*}{ 2013-2014, phase 1 } & 1 & $\begin{array}{l}\text { Dhaka, Ghagipur, Narsingdi, Narayanganj, Tangail, Jamalpur, } \\
\text { Mymensingh, Kishoregonj. }\end{array}$ \\
\cline { 2 - 3 } & 2 & $\begin{array}{l}\text { Dinajpur, Gaibandha, Jaipurhat, Bogra, Naogaon, Nator, } \\
\text { Sirajgonj, Rajshahi, Chapai, Nawabganj, Rangpur. }\end{array}$ \\
\hline \multirow{3}{*}{ 2014-2015, phase 2 } & 1 & Dhaka, Comilla, Munshiganj, Narayanganj. \\
\cline { 2 - 3 } & 2 & Barisal, Jhalokati, Pirojpur, Patuakhali, Barguna, Satkhira. \\
\cline { 2 - 3 } & 3 & Madaripur, Gopalganj, Narail, Jessore, Bagerhat, Khulna. \\
\hline \multirow{3}{*}{ 2015-2016, phase 3 } & 1 & $\begin{array}{c}\text { Sylhet, Moulavi Bazar, Sunamgonj, Hobigonj, Brahmanbaria, } \\
\text { Netrokona \& Kishoregonj. }\end{array}$ \\
\cline { 2 - 3 } & 2 & Noakhali, Feni, Bhola, Chittagong, Dohajari and Cox's Bazar. \\
\cline { 2 - 3 } & 3 & Kushtia, Meherpur, Chuadanga, Jhenaidah, and Magura. \\
\cline { 2 - 3 } & 4 & Panchgarh, Thakurgaon and Dinajpur. \\
\hline
\end{tabular}

Another aspect of this paper is flood hazard assessment as per all roads of Bangladesh. For this, we considered elevation of the areas with the existing road network. A digital elevation model (DEM) is a digital model or 3D representation of a terrain's surface — commonly for a planet (including Earth), moon, or asteroidcreated from terrain elevation data.A Digital Elevation Model (DEM) is a digital cartographic/geographic dataset of elevations in xyz coordinates. The terrain elevations for ground positions are sampled at regularly spaced horizontal intervals. DEMs are derived from hypsographic data (contour lines) and/or photogrammetric methods using USGS 7.5-minute, 15-minute, 2 -arc-second (30- by 60-minute), and 1-degree (1:250,000-scale) topographic quadrangle maps. In this study, we used $30 \mathrm{~m}$ resolution DEM for elevation model of Bangladesh along with road network (Fig. 5).

\section{Discussions}

Fig. 4 manifests roads of Bangladesh along the characteristic consistency of soils they are lying upon. Can be observed from the map that about 17,000 Km road-network of RHD. On top of that, there can be seen around $1057 \mathrm{Km}$ of roads lying on soft soil. Besides, locations where marshy clay and peat are exposed and the road thereby can also be seen on this map.Peaty soils and marshy clays in the surface area is an indication of a swampy and humid environment of present active river plain deposits. In these soils, partially or wholly decomposed organic matter are present. These soils have a low infrastructure and of low quality on engineering value. Peat and muck layers are black to dark brown, strongly reduced, and neutral in reaction under persisting conditions. When these layers are allowed to dry, they become extensively acidic. The unit is seasonally flooded by both increased river water and rainwater hence, remains wet around this time. During the dry season where mineral topsoil is present they become dry. Under dry condition mineral top-soils are mainly grey or dark grey and become strongly acidic. The soil has generally low agricultural productivity.

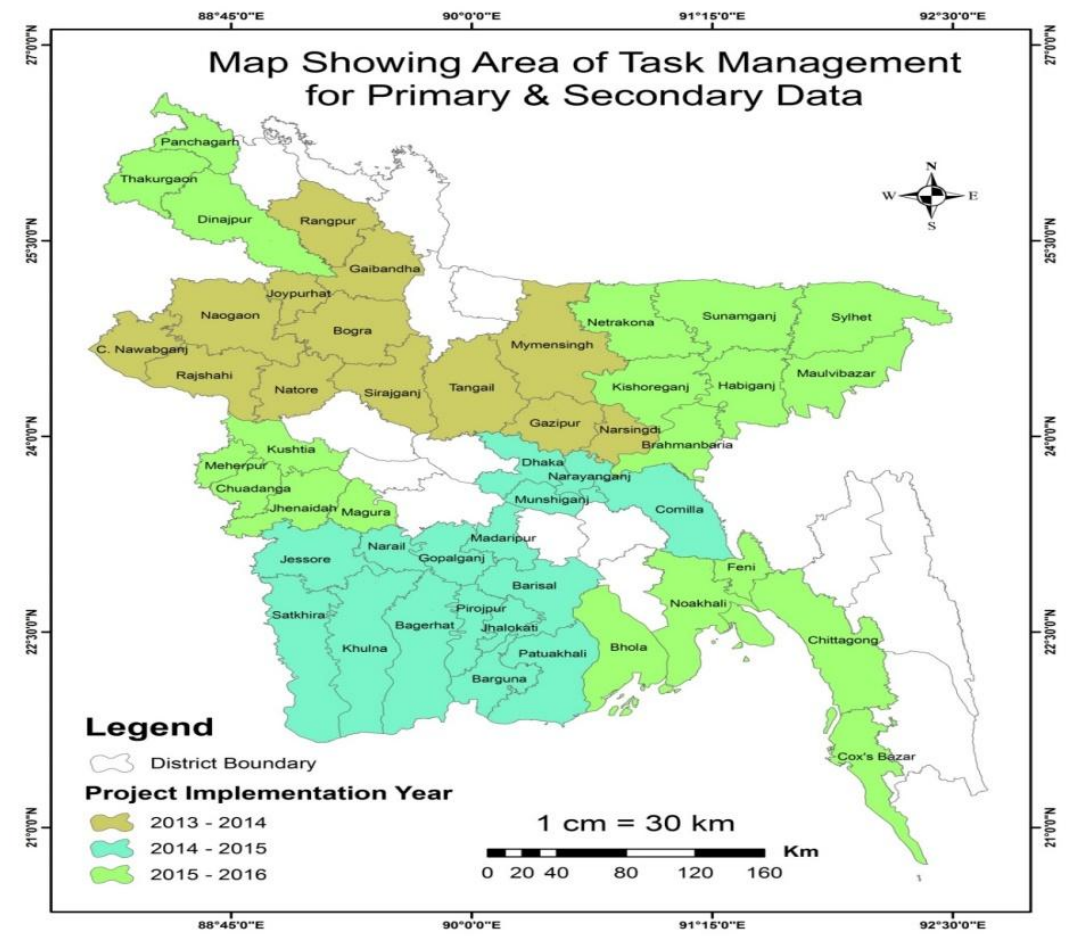

Figure 3: Accomplished engineering soil mapping locations at three financial years. 


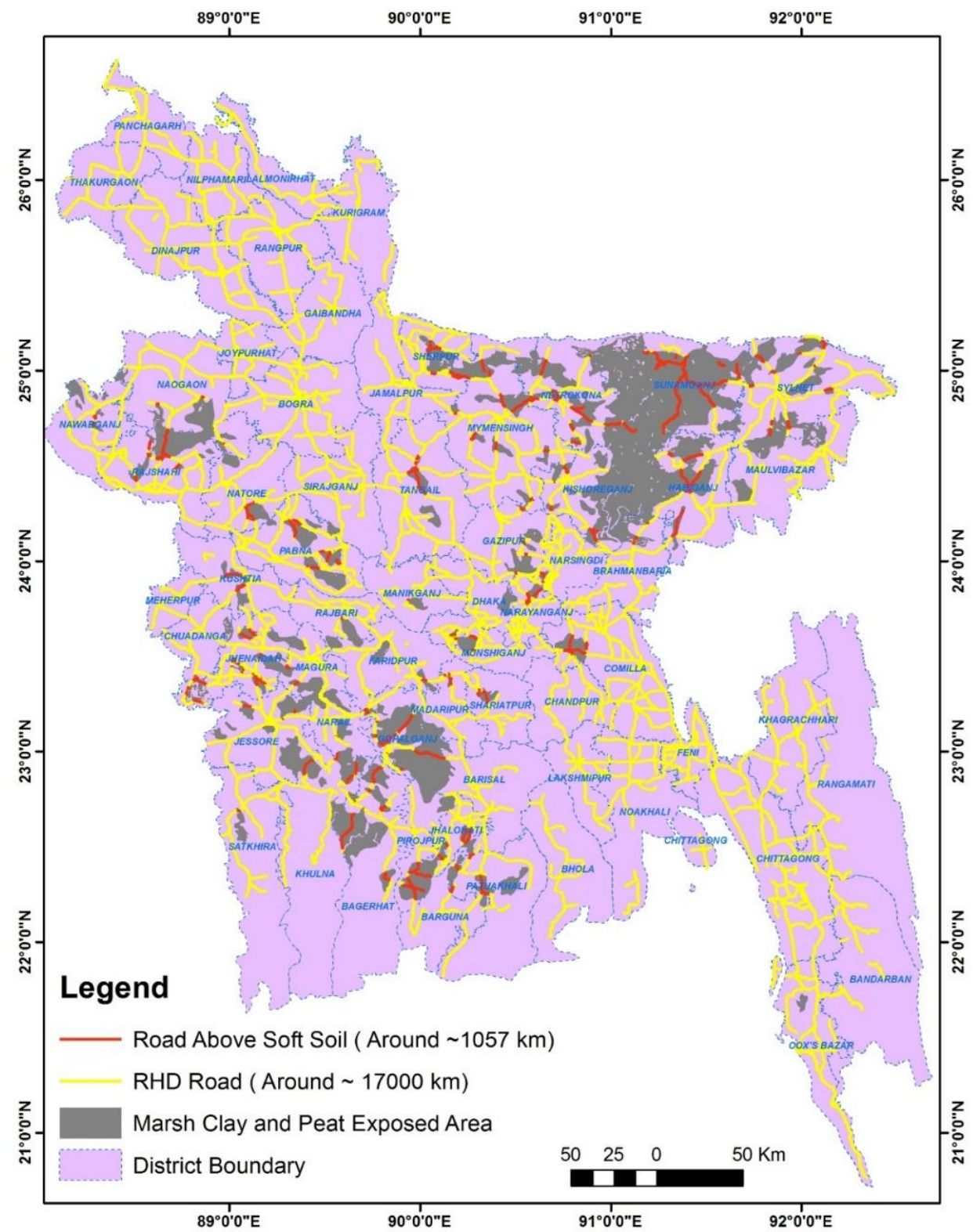

Figure 4: Map of road network and respective soil condition of Bangladesh.

On the map, marshy clay and peat deposits are seen exposed largely in the north, east, and south of Sylhet division. To the west, some northern areas of Mymensingh district are also seen to have these depositions exposed on the surface. Moreover, a number of roads are seen running on these deposits. These deposits are also seen exposed in small areas around Dhaka division, across which also there are roads running. Marshy clay and peat deposits are also exposed in Rajshahi division. They are located in northeast, middle part and south of the division. A number of roads are seen running through these soils. These types of deposits has also been found sporadically in small discrete locations of Khulna division. But they are concentrated in the north, and middle part of the division. There, the roads are also running on these type of soils. These deposits are also present in the western and southwestern part of Barisal division, where there roads have been constructed as well.

As marshy clay and peat are very low in consistency, they have much lower engineering value for building civil infrastructure and critical lifeline like roads, etc. on them. Roads on these types of soils have very poor longevity, so should be avoided for maximum economic benefit. Otherwise, ground improvement measures should be taken if in case cannot be avoided for any constraint. Before construction of road in any locality, detailed survey should be taken for exploring such weak soils. 


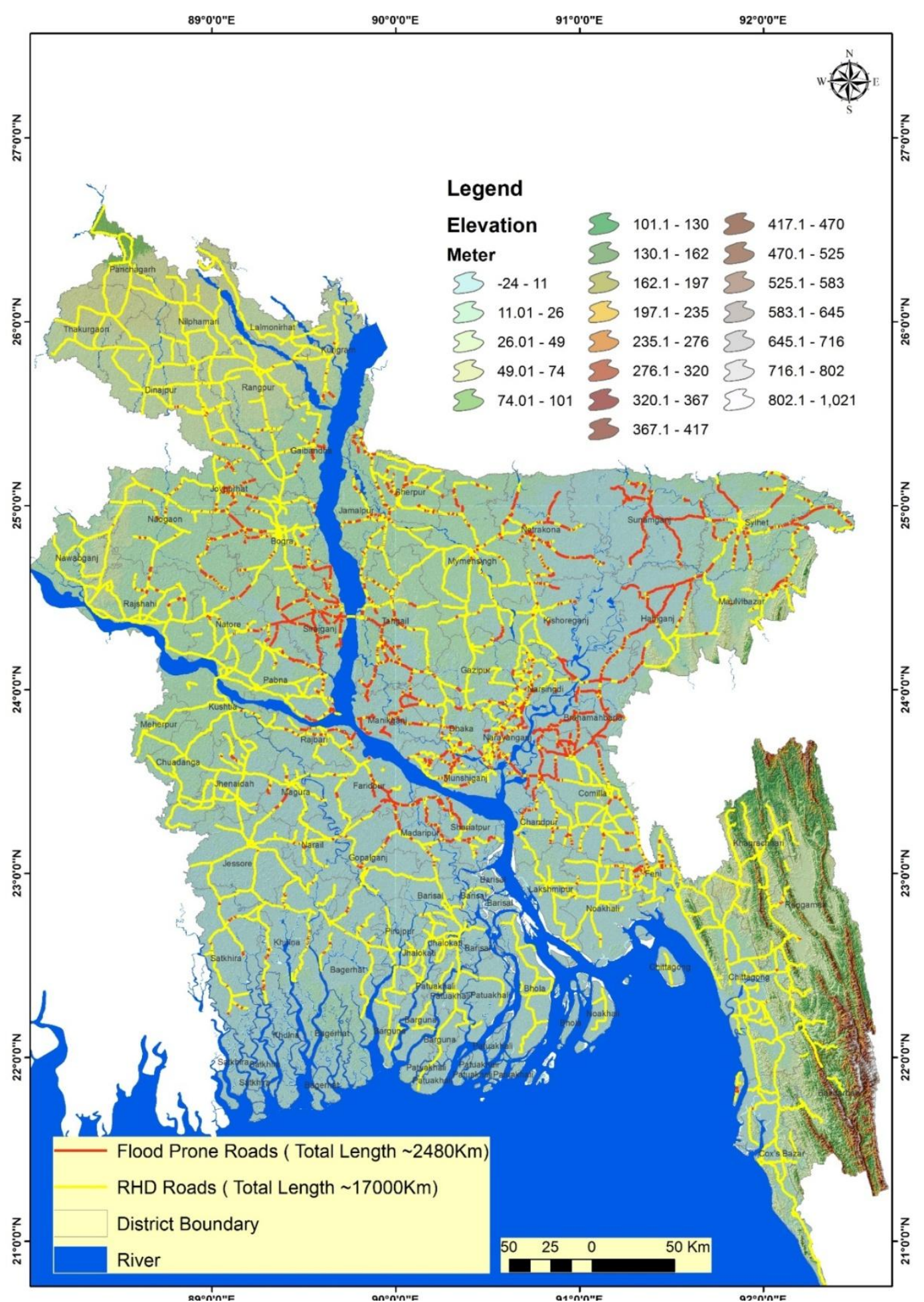

Figure 5: Flood vulnerability of roads of Bangladesh with respect to elevation.

The map shows the road-network around Bangladesh with respect to elevation (Fig. 5). The map also indicates roads in flood prone areas while others are not much prone to the disaster. It can be seen that around $2480 \mathrm{Km}$ roads lye on lowly elevated areas, and around 15,000 Km roads lye on areas with comparatively high elevation.

Bangladesh is a flood prone country where this natural hazard strikes as disaster in almost every year. Alike most common natural hazards it also causes loss of life, properties and infrastructures. Roads are one of the worst hits of flood, causing economic loss by interrupting normal transport systems and for maintenance. That is why the development of database about flood prone areas should be one of the top most elements while planning for establishing road-network in any location of Bangladesh: so that runoff areas during flood can be 
avoided, or proper measures can be taken if unavoidable anywhere. From this point of view, this project also aims at delineating the location wise status of flood effect all around Bangladesh. The elevation map in of the country has been used here as a mean of anticipating flood hazard effect all over (Fig. 5). It seems from the map that the northern most area of Bangladesh, i.e., Panchagarh district, is less likely for being affected by flood for its elevation of about 162.1 to $197 \mathrm{~m}$. The adjacent areas, further south, also have a considerably good elevation, i.e., 130.1 to $162 \mathrm{~m}$, for not being flood prone, which include Rangpur, Dinajpur, Lalmonirhat, Nilfamari, and Thakurgon districts in the northern portion of Rajshahi division. Elevation continues to decrease further south of the division-74.01 to $101 \mathrm{~m}$ - and so also less likely to be flood prone. But, the Padma and the Jamuna River floodplain areas are always in risk of heavy flood. Khulna division is further south of Rajshahi division and the Padma River. Northerly Meherpur, Kushtia, Chuadanga, and Jhenaidah districts of Khulna division have elevation as that of the adjacent part of Rajshahi division, i.e., 74.01 to $101 \mathrm{~m}$. These areas may experience low effect of flood. Elevation in this division becomes lower southerly from 26 to $74 \mathrm{~m}$ and thus can be moderately affected. Coastal areas have much less elevation: 11 to $26 \mathrm{~m}$. These areas can be severely affected during flood. Coastal areas very close to the Bay of Bengal have elevation from -24 to $11 \mathrm{~m}$; these areas may suffer severe tidal surge. Barisal division is situated to the east of Khulna division, and has a nearly similar topographic pattern, so has moderate to severe flood threat from north to south. Northern part of the Mymensingh has elevation from 130.1 to $162 \mathrm{~m}$, so could be excluded from monsoonal flood risk. Elevation decreases to 101 to $74.01 \mathrm{~m}$ southward, where risk of the said natural hazard might be low. But the areas within the Brahmaputra River and the Jamuna River floodplain could be of moderate to severe risk. To the east of Mymensingh division is situated Sylhet division. Sylhet division also has higher topography in the northern extreme-elevation ranging from 130.1 to $162 \mathrm{~m}$. So, these areas are less risky for monsoonal flood hazard. Elevation decreases from 101 to $74.01 \mathrm{~m}$ towards south, so could be of low risk. Dhaka division is situated in the central Bangladesh. In Dhaka division elevation varies from 49.01 to $74 \mathrm{~m}$ in the middle part, Dhaka and Gazipur districts, so this locality is moderate to low flood prone. Tangail and Munsiganj districts in the east and south of Dhaka division, respectively, are near the Meghna River and the Jamuna River, where elevation is 26.01 to $46 \mathrm{~m}$ and moderate to severe risk of river flooding. Narshingdi and Narayanganj districts lye in the east of Dhaka division, where elevation is 11.01 to $26 \mathrm{~m}$ and thus have low to moderate flood risk. Brahmanbaria district of Chittagong division is situated in east-central Bangladesh, where elevation varies from 11.01 to $26 \mathrm{~m}$. So, this area might have low to moderate flood risk. To the south of this district is situated Komilla district, where elevation is same and so the flood risk. Chadpur and Laksmipur districts are situated in southern Bangladesh and in the east of Chittagong division. These districts have elevation from 11 to $26 \mathrm{~m}$, rendering low to moderate flood risk. Noakhali and Feni might be equally flood prone. But areas adjacent to the coast would suffer severe tidal surge. Elevation in the areas of the eastern part of Chittagong division is very high, 130.1 to $1,021 \mathrm{~m}$, so these localities are devoid of flood risk. But flash flood may occur during the monsoon. But in the southern part of Chittagong district elevation is low, i.e., less than $11 \mathrm{~m}$, where severe tidal surge may take place.As a whole, it can be concluded that areas within the river flood plain are low in elevation and could be affected by flood during monsoon. Moreover, coastal regions are really lowly elevated and tidal surge can cause significant damage to road network these localities.

\section{Conclusion}

This article makes a review on the present status of existing road network with respect to the soil condition they are lying on alongside recommending for future roads. Besides, this research also includes an evaluation of flood hazard vulnerability of the existing road network and also enclose recommendation for future work. It has been revealed from the study that roads are in some areas lying on soft soils, which have low to very low strength. Moreover, there roads somewhere are as such that highly vulnerable for being affected by flood hazard. These areas should be avoided for cost effectiveness of the road network of Bangladesh or taken proper ground improve measure. This paper suggests proper engineering investigation before planning for future roads and adequate maintenance of the present roads.

\section{Acknowledgements}

This article was supported by Roads and Highway Department (RHD) of BangladeshRoad Research Laboratory (BRRL) under RHD of Government of the Peoples' Republic of Bangladesh.Our thanks to M. Ahmed \& Accosiate Ltd., Environmental \&Geospatial Solutions, Prosoil Foundation Consultant and NoorZaman Engineering Foundation for collecting and providing relevant data.

\section{References}

[1] M.S. Steckler, S.H. Akhter,and L. Seeber, Collision of the Ganges-Brahmaputra Delta with the Burma Arc: Implications for earthquake hazard,Earth and Planetary Science Letters, 273,2008, 367-378.

[2] Roads and Highways Departments (RHD), Final report on Preparation of soil maps for remaining divisions and compilation of soil maps prepared in the previous year under BRRL during the year 2016-2017, 2017. 
[3] A. Uddin, and N. Lundberg, Miocene sedimentation and subsidence during continent-continent collision, Bengal Basin, Bangladesh,Sedimentary Geology, 164, 2004,131-146.

[4] M.A. Islam,S. Murshed,S.M.M. Kabir, A.H. Farazi, M.Y. Gazi, I. Jahan, and S.H. Akhter, Utilization of open source spatial data for landslide susceptibility mapping at Chittagong district of Bangladesh - an appraisal for disaster risk reduction and mitigation approach. International Journal of Geosciences, 8, 2017,577-598. https://doi.org/10.4236/ijg.2017.84031

[5] M.Z. Rahman, M.S. Hossain, A.S.M.M. Kamal, S. Siddiqua, F. Mustahid, and A.H. Farazi, Seismic site characterization for Moulvibazar town, Bangladesh,Bulletin of Engineering Geology and the Environment, 2017, 1-21. doi:10.1007/s10064-017-1031-6

[6] M. Alam, M.M. Alam, J.R. Curray, M.L.R. Chowdhury, and M.R. Gani, An overview of the sedimentary geology of the Bengal Basin in relation to the regional tectonic framework and basin-fill history, Sedimentary Geology, 155, 2003, 179-208.

Md. Abdullah Al Mamun. "An Evaluation Of Soil Condition And Flood Risk Forroad Network Of Bangladesh - Compiled From Engineering Soil Maps And Digital Elevation Model." IOSR Journal of Mechanical and Civil Engineering (IOSR-JMCE) 14.4 (2017): 53-61. 